\title{
Detection of Hepatitis B Virus in the Aqueous Humor of a Hepatitis B Virus Carrier
}

\author{
Ching-Yao Tsai ${ }^{a, c}$ Chih-Lin Lin ${ }^{b}$ Shiao-Cheng Lin ${ }^{a}$ Shiow-Wen Liou ${ }^{a, d}$
}

Departments of a Ophthalmology and ${ }^{b}$ Gastroenterology, Taipei City Hospital, ${ }^{c}$ Community Medicine Research Center and Institute of Public Health, National Yang-Ming University, and d Department of Ophthalmology, Taipei Medical University, Taipei, Taiwan, ROC

\section{Key Words}

Hepatitis B virus · Aqueous humor · Polymerase chain reaction, eye

\begin{abstract}
The prevalence of hepatitis B virus (HBV) is particularly high in Asian countries, including Taiwan. Previous studies have reported detection of HBV surface antigens in tears and aqueous humor of HBV-seropositive individuals, suggesting that ophthalmologists may be at risk of contracting HBV infection by treatment of such patients. Herein we report the case of an asymptomatic Taiwanese HBV patient in whom HBV was detected in aqueous humor using PCR. To our knowledge this is the first report of HBV detection in aqueous humor by PCR. Eye care providers should take all necessary precautions when treating individuals who have or are at high risk of being infected with HBV.
\end{abstract}

Copyright $\odot 2008$ S. Karger AG, Basel

\section{Introduction}

Several studies have reported the detection of hepatitis $B$ virus (HBV) surface antigens (HBsAg) in tears and aqueous humor $[1,2]$, suggesting that eye care practitioners may be at a high risk of contracting HBV infection and transmitting the virus when treating afflicted individuals. In Asian countries, such as China and Taiwan where the prevalence of HBV infection is especially high [3], this possibility is an added concern. Here we report the case of an otherwise (HBV) asymptomatic Taiwanese patient in whom HBV was detected in aqueous humor by qualitative polymerase chain reaction (PCR).

\section{Case Report}

A 60-year-old female previously found to be an HBV carrier presented with cataract-associated impaired vision of the right eye. Two years earlier the patient had undergone phacoemulsification and intraocular lens insertion of the left eye resulting in postoperative visual acuity of 6/6. At admission, visual acuities of the right and left eye were 0.1 and 1.0, respectively. Neither diabetic retinopathy nor maculopathy were apparent, and the patient was scheduled for cataract surgery. The patient's serum tested positive for HBsAg and negative for the HCV antibody. Prior to surgery, the patient consented to provide an aqueous humor sample for HBV detection.

The right eye was prepared with $5 \%$ povidone-iodine after full dilation of the pupil with $1 \%$ Mydriacyl. Retrobulbar anesthesia was induced using $2 \mathrm{ml}$ of $2 \%$ lidocaine. Prior to clear corneal phacoemulsification, anterior chamber paracentesis was performed using a 30 -gauge needle, and $0.25 \mathrm{ml}$ of aqueous humor was extracted for analysis. Postoperative recovery was uneventful.

\section{KARGER \\ Fax +41613061234 E-Mail karger@karger.ch} www.karger.com

\section{(0) 2008 S. Karger AG, Basel}

$0030-3755 / 09 / 2232-0093 \$ 26.00 / 0$

Accessible online at:

www.karger.com/oph
Shiow-Wen Liou

Department of Ophthalmology, Taipei City Hospital

145 Zheng Zhou Road

Taipei 103, Taiwan (ROC)

Tel. +8862 2552 3234, ext. 6283, Fax +88622737 5042, E-Mail dae77@tpech.gov.tw 
The identification of HBV genome and genotype was performed by PCR using specific primers for genotypes B and C, which predominate in Asian populations [4]. Briefly, DNA was extracted from aqueous humor using a QIAamp blood kit (Qiagen, Chatsworth, Calif., USA), and the HBV genome fragments were amplified. For HBV genotype B, the outer sense primer was 5'-TCACCATATTCTTGGGAACAAGA-3' (nucleotide positions 2825-2847), the outer antisense primer was 5'-CGAACCACTGAACAAATGGC-3' (nucleotide positions 706-687), the inner sense primer was 5'-GGCTCCAGTTCAGGAACAGT-3' (nucleotide positions 67-86) and the inner antisense primer was 5'-CAGGTTGGTGAGTGACTGGAGA-3' (nucleotide positions 347-326). For HBV genotype $C$, the outer sense primer was 5'-TCACCATATTCTTGGGAACAAGA-3' (nucleotide positions 2825-2847), the outer antisense primer was $5^{\prime}$-CGAACCACTGAACAAATGGC -3' (nucleotide positions 706-687), the inner sense primer was 5'-GGCTCCAGTTCAGGAACAGT-3' (nucleotide positions 67-86) and the inner antisense primer was 5'-GGTCCTAGGAATCCTGATGTTG-3' (nucleotide positions $188-167)$. For the first PCR stage, $25 \mu \mathrm{l}$ of reaction mixture containing $2 \mu$ l of the DNA sample, $1 \times$ PCR buffer $(10 \mathrm{~mm}$ Tris- $\mathrm{HCl}$, $\mathrm{pH} 9.0,50 \mathrm{mM} \mathrm{KCl}, 1.5 \mathrm{mM} \mathrm{MgCl}_{2}, 0.01 \%$ gelatin and $0.1 \%$ Triton X-100), $10 \mathrm{mM}$ of each dNTP, $100 \mathrm{ng}$ of each outer primer and 1 unit of Taq DNA polymerase was amplified in a thermal cycler (Perkin-Elmer Cetus, Norwalk, Conn., USA) for 35 cycles. Each cycle consisted of denaturation at $95^{\circ} \mathrm{C}$ for $60 \mathrm{~s}$, primer annealing at $52^{\circ} \mathrm{C}$ for $30 \mathrm{~s}$ and extension at $72^{\circ} \mathrm{C}$ for $60 \mathrm{~s}$ with a final extension step at $72^{\circ} \mathrm{C}$ for $10 \mathrm{~min}$. After the first amplification, $1 \mu \mathrm{l}$ of the PCR product was re-amplified for another 35 cycles with 100 ng of each inner primer.

PCR products were electrophoresed on a 3\% agarose gel and stained with ethidium bromide. A 281-base-pair PCR product was detected, indicating the HBV genotype B.

\section{Discussion}

HBV is present in body fluids, such as blood, saliva, semen, vaginal secretions and menstrual blood of infected individuals. As HBV is resistant to breakdown outside the body, it is readily transmitted from person to person via contact with infected bodily fluids [5]. Asymptomatic HBV carriers serve as reservoirs of infection within the community and suffer increased risks for chronic liver disease and hepatocellular carcinomas [6].
Currently, HBV is classified into 8 genotypes (A-H), based on an intergroup divergence of more than $8 \%$ in the complete nucleotide sequence of viral genomes [7]. These genotypes have distinct geographical distributions and disease courses [4]. The B and C HBV genotypes are predominant in Taiwan [8]. Individuals with type C HBV tend to suffer from severer liver disease than those with type B infections [9]. At this stage, it is not known whether the transmission of HBV varies with genotype.

Eye care providers are exposed to infectious disease risk via contact with tears and aqueous humor. Although no definitive cases have been published, it is plausible that HBV may be transmitted from infected patient to ophthalmologist via these media. A number of studies have reported the detection of HBsAg in tears and aqueous humor of HBsAg seropositive patients $[1,2]$. Temel et al. [1] noted that 7 of $10 \mathrm{HBsAg-seropositive} \mathrm{patients} \mathrm{also}$ tested positive for HBsAg in tear and aqueous humor samples on the day of cataract surgery. Similarly, Koksal et al. [2] found that $85 \%$ of HBsAg-positive patients also tested positive for HBsAg in tear samples. To our knowledge, the current study is the first to report detection of $\mathrm{HBV}$ in aqueous humor using PCR methodology. A previous publication failed to detect $\mathrm{HBV}$ in vitreous humor of HBV carriers using PCR, despite the fact that serum from several of these patients was found to be HBV positive by PCR analysis [10]. Interestingly, Kobayakawa et al. [11] reported that close to $50 \%$ of $\mathrm{HCV}$-antibody-positive patients also tested positive for $\mathrm{HCV}$ in aqueous humor as determined by PCR. It would seem that while HBV is almost certainly present in tears and aqueous and vitreous humor, in some cases levels may be so low as to be undetectable by the present methods. Whether ocular fluids from such individuals possess any infectious risk is unknown. In any case, the findings from our and other reports reiterate that ophthalmologists and other eye care providers should take all necessary precautions in both the surgical and nonsurgical treatments of patients at high risk for hepatitis B infection.
References
1 Temel A, Seber E, Gunay M: Detection of hepatitis B surface antigen in aqueous humor. Acta Ophthalmol (Copenh) 1990;68: 205-208.

2 Koksal I, Cetinkaya K, Aker F: Hepatitis B surface antigen in tears and aqueous humor: a comparative study of serum hepatitis B surface antigen levels. Ophthalmologica 1992;204:19-22.
Merican I, Guan R, Amarapuka D, Alexander MJ, Chutaputti A, Chien RN, Hasnian SS, Leung N, Lesmana L, Phiet PH, Sjalfoellah Noer HM, Sollano J, Sun HS, Xu DZ: Chronic hepatitis B virus infection in Asian countries. J Gastroenterol Hepatol 2000;15: 1356-1361. 
4 Schaefer S: Hepatitis B virus: significance of genotypes. J Viral Hepat 2005;12:111-124.

5 Lavanchy D: Hepatitis B virus epidemiology, disease burden, treatment, and current and emerging prevention and control measures. J Viral Hepat 2004;11:97-107.

6 Chen DS: Viral hepatitis: from A to E, and beyond? J Formos Med Assoc 2003;102:671679 .
Okamoto H, Tsuda F, Sakugawa H, Sastrosoewignjo RI, Imai M, Miyakawa Y, Mayumi M: Typing hepatitis B virus by homology in nucleotide sequence: comparison of surface antigen subtypes. J Gen Virol 1988;69:25752583.

8 Lin CL, Liao LY, Wang CS, Chen PJ, Lai MY, Chen DS, Kao JH: Basal core-promoter mutant of hepatitis B virus and progression of liver disease in hepatitis $B$ e antigen-negative chronic hepatitis B. Liver Int 2005;25:564570.

-9 Kao JH, Chen PJ, Lai MY, Chen DS: Genotypes and clinical phenotypes of hepatitis $B$ virus in patients with chronic hepatitis $\mathrm{B}$ virus infection. J Clin Microbiol 2002;40: 1207-1209.
10 Aras C, Ozdamar A, Ergin S, Ozturk R, Midilli K, Karacorlu M, Ozkan S: Failure to detect hepatitis B virus in vitreous by polymerase chain reaction. Ophthalmologica 2005;219:93-96.

-11 Kobayakawa S, Tochikubo T, Watanabe H, Nomura N: Hepatitis $\mathrm{C}$ virus in the aqueous humor (in Japanese). Nippon Ganka Gakkai Zasshi 1993;97:1061-1064. 